\title{
MODOS DE VIGENCIA Y RESIGNIFICACIÓN DE COMIDAS TRADICIONALES EN VALLES Y PUNA DE BELÉN, CATAMARCA
}

\author{
Re-signification and re-validation of traditional gastronomy in Puna Valleys, Belén, Catamarca, Argentina
}

\section{Cecilia Pernasetti}

Universidad Nacional de Córdoba - UNC - Córdoba - Argentina

María Florencia Ferre

Investigadora independiente

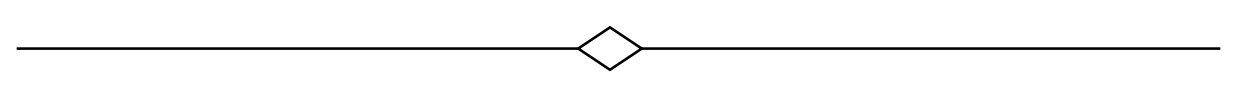

Resumo: Entre los años 2009 y 2013 realizamos un relevamiento de más de 60 preparaciones tradicionales de alimentos salados, dulces y bebidas en localidades del departamento Belén, Provincia de Catamarca (comunidades de valles, prepuna y puna) a través de observación participantes y entrevistas (historias de vida). Después de una definición de lo que entendemos por gastronomía tradicional y una descripción de los alimentos relevados, en el presente trabajo intentaremos responder: ¿Cuándo un plato se considera como parte de la cocina tradicional? ¿Cómo llega a entrar en ese repertorio? ¿Por qué algunos alimentos forman parte de este repertorio y otros no? Identificamos un primer rasgo diferencial de lo que se considera comida tradicional que pasa por el tipo de comensalidad --entendida como la ocasión y el modo en que estas comidas se consumen y se comparten--, predominantemente colectiva. Vamos a tomar este concepto y lo vincularemos con una sugerencia de Arjun Appadurai acerca de los procesos de re-significación que hacen que una comida se independice de sus sentidos iniciales y pase por un proceso de distanciamiento tal que logra ser cargada con significaciones que la hacen propicia para ser representativa de un sistema o modo culinario. Retomando estas ideas podemos decir que gran parte de los alimentos que nos fueron señalados como tradicionales han sufrido un proceso de re-significación y re-valoración, en más de un sentido. El análisis de estos procesos de re-significación nos permitió reconocer tanto el carácter "tradicional" de las preparaciones alimentarias relevadas como sus modos de vigencia, que son diversos.

Palavras-chave: Gastronomía tradicional. Memorias colectivas. Noroeste argentino.

Abstract: From 2009 to 2013 we surveyed more than 60 traditional dishes including food preparations and beverages, in different localities spreading the department of Belén, in the Province of Catamarca, Argentina (where communities can be found in the valleys, prepuna and puna). The survey included observation, direct participation and unstructured, in-depth interviews. After defining traditional gastronomy and describing the surveyed preparations, we will try to answer to the following questions: ¿When is a dish considered part of the traditional gastronomy? ¿In what ways does it enter the repertoire of traditional gastronomy? ¿Why does one dish get to be considered traditional while others do not? We identify one first distinguishable aspect of the traditional food concearning its commensality -the time and ways of sharing food and eating together-, which is being shared by large numbers of people. We will take the concept of commensality and relate it to Arjun Appadurai's processes of resignifying a dish in order to set it apart from its original meanings and assign it new significations which make it representative of a culinary system. Many of the dishes which were at first pointed to us as traditional, have undergone a process of resignification and reestimation. The analysis of these processes enables us to identify these preparations as traditional as well as to asset their validity within the communities.

Keywords: Traditional gastronomy. Collective memories. Argentinian Northwest. 
Entre abril de 2009 y febrero de 2013, realizamos un relevamiento de alimentos tradicionales en la ciudad de Belén y los pueblos de Villa Vil, Barranca Larga, Los Morteritos, Laguna Blanca, y El Durazno, pertenecientes al Departamento Belén, al NO de la provincia de Catamarca'. El objetivo de esta investigación fue registrar, recopilar y fotografiar las comidas $y$ preparaciones diversas, tanto saladas como dulces que en la zona descrita se consideran como comida tradicional y asociado con esto también indagar en qué medida dichos alimentos se preparan con ingredientes producidos de manera local, ya sea de producción familiar, de la comunidad o de la región. Es decir, no indagamos acerca de la comida cotidiana, habitual de una comunidad sino acerca de aquella que los miembros de la comunidad señalan como característica o "típica" de su pueblo o región. Realizamos entrevistas no estructuradas además de observación participante que incluyó la participación en la preparación de algunos de los alimentos, el registro fotográfico de esas preparaciones, y de los pueblos, casas, cocinas y de algunas de las personas entrevistadas ${ }^{2}$. En las cuatro localidades visitadas se relevó un listado de 60 alimentos, y se registró fotográficamente la preparación de 15 de ellos (Ver anexo 1). Sin embargo, la experiencia de las entrevistas y la observación etnográfica nos permiten suponer que la lista de alimentos y sobre todo de sus variaciones se ampliaría con la visita a pueblos vecinos 0 incluso con nuevas entrevistas a otras familias de los mismos pueblos. A continuación realizaremos una breve descripción del área de estudio y en seguida haremos referencia a los alimentos relevados y los sentidos involucrados en lo

\footnotetext{
${ }^{1}$ Parte de esta investigación fue publicada en: Ferre, Florencia y Cecilia Pernasetti (2013): Inventario de sabores. Un viaje por la cocina tradicional de Belén, editado por la Secretaría de Cultura de la Provincia de Catamarca

${ }^{2}$ Se entrevistaron 15 personas correspondientes a 10 familias en Belén, 13 personas ( 7 familias) en Termas de Villavil, 6 personas (4 familias) en Laguna Blanca, 4 personas (una familia) en E Durazno, 4 personas (2 familias en Los Morteritos) y una persona en Barranca Larga
}

que nuestros entrevistados indicaron como parte de su cocina tradicional.

\section{1 Área de estudio}

El departamento Belén, tiene una extensión de $12.945 \mathrm{~km}^{2}$, de 27.843 habitantes (censo 2010). La ciudad de Belén, cabecera municipal, concentra la mayor parte de esa población (12.256 habitantes según censo 2010) y el resto se encuentra dispersa en numerosos pueblos y caseríos; como centro administrativo es el eje que aglutina las actividades administrativas y económicas del departamento. E departamento es montañoso en su totalidad, con valles fértiles seguidos de desiertos y un sector correspondiente a la puna, meseta andina ubicada entre 3.500 y $4.200 \mathrm{msnm}$.

El distrito de Villavil, pertenece al departamento Belén y está ubicado al NO de la ciudad de Belén, tiene una población total de 2.160 habitantes (censo 2010) Abarca territorios correspondientes precordillera, prepuna y puna, incluye el pueblo del mismo nombre, cabecera municipal, y los pueblos de Barranca Larga, Morteritos, Las cuevas y Laguna Blanca (500 habitantes), este último, localizado en la puna, está dentro de la Reserva de la Biósfera del mismo nombre -reserva natural de vida silvestre con una superficie de 700.000 hectáreas--, creada con el propósito de preservar, mejorar y revalorizar a los camélidos, fundamentalmente a las vicuñas.

El Durazno, con 657 habitantes (censo 2010) está ubicado en el distrito de La Puerta de Corral Quemado, $100 \mathrm{~km}$ al norte de la ciudad de Belén. Se caracteriza por su cerros de colores rojizos, morados y azules, llamados "jasis", y pequeños arroyos o aguadas que alimentan viñas, nogales, frutales y huertas.

El área visitada tiene, respecto al resto del país, una historia de sostenido aislamiento. Cuando los españoles arribaron a esas tierras se encontraron con villas de importancia que contaban con un notable desarrollo de la agricultura, la ganadería de llamas, vicuñas, guanacos, y que producían delicados textiles, cerámicas y metales. Algunas de estas poblaciones estaban bajo el reciente dominio del imperio Inca. 
Durante los primeros años de las colonias españolas en América, fue el noroeste argentino una de las primeras zonas en poblarse de españoles ${ }^{3}$. Dependía cultural y administrativamente de Chile y Perú y hasta inicios del S $X X$ la comunicación y el intercambio comercial con poblaciones de estos países y Bolivia era más asidua y regular que con el Río de la Plata. En la época de las grandes migraciones europeas de fines del siglo XIX y principios del siglo $X X$, el noroeste no acogió a las comunidades italianas, españolas, alemanas y centroeuropeas, tal como sucedió en Córdoba, Santa Fe, La Pampa y las provincias del noreste. Alguno que otro italiano se aventuraba a llegar a estas tierras lejanas, que sí fueron el destino elegido por pequeños grupos de inmigrantes sirio-libaneses.

Durante el desarrollo moderno de la Argentina "granero del mundo" de principios del siglo XX, y de la industria de la segunda mitad del siglo, el noroeste quedó fuera del esquema planteado para un país centralizado en Buenos Aires y sustentado por la producción de cereales y de carne vacuna: las montañas ásperas y la lejanía del puerto, eran entonces desventajas que obstaculizaban el ingreso a la bonanza económica. Así como las producciones locales tenían dificultades en llegar al resto del país, tampoco aquellas que provenían de las provincias del sur tenían muchas facilidades para comerciarse en el noroeste. Dentro de la provincia de Catamarca la ciudad de Belén y los pueblos aledaños del norte eran zona de paso de caravanas de mulas que llevaban y traían mercaderías a Chile, hasta las primeras décadas del siglo XX. Las migraciones a los centros urbanos y a la Patagonia fueron persistentes desde mediados del $S \mathrm{XX}$ y aumentaron durante los años noventa.

Otra de las fuentes de trabajo e ingreso históricos en el oeste catamarqueño fue la minería, y su explotación se practicaba desde tiempos precolombinos. Alcanzó un primer auge en la segunda mitad del siglo XIX, sobre todo en la zona de Andalgalá, que conlinda con el departamento Belén. La minería decayó a fines del XIX y sólo pudo recuperar su importancia a fines del SXX con la explotación a gran escala. En el municipio

\footnotetext{
${ }^{3}$ Londres, a $15 \mathrm{~km}$ de la ciudad de Belén, fue la segunda población fundada por los españoles, en 1558, después de Santiago del Estero (1550).
}

de Belén se encuentra Bajo la Alumbrera, uno de los emprendimientos mineros más importantes de Latinoamérica. Comenzó su producción de cobre y oro en 1997. Para el año 2007 la explotación convirtió a Catamarca en la provincia de mayor producción de minerales metálicos del país (75\%). Sin embargo, no ha tenido influencia considerable en la economía de la zona visitada ${ }^{4}$.

Respecto a la producción agropecuaria, según el Censo Nacional Agropecuario de 2002, en el departamento de Belén el 92,8 \% de las explotaciones agropecuarias están en el estrato de los productores minifundistas (una superficie de hasta 25 hectáreas) y cubren el 3,84\% de la superficie total; el $70 \%$ de las explotaciones tiene menos de 5 ha. Mientras que 2 de estas explotaciones agropecuarias $(0,1 \%)$ de más de 10.000 ha cubren el $88,7 \%$ de la superficie total, en este caso se trata de grandes extensiones de campo virgen en la puna y la montaña, no implantados, que mayormente se usa para pastoreo. El departamento Belén es el principal productor de nogal de la provincia, le siguen en importancia las producciones de aromáticas (comino y anís) vid, pimentón, higueras, hortalizas y otros frutales para consumo regional. Es importante en todo el departamento como fuente de ingresos familiares el hilado de fibra y la elaboración de tejidos de lana de oveja, llama y vicuña, según técnicas tradicionales. Sus productos textiles son reconocidos en todo el país.

En los pueblos visitados el ingreso extra-predial más importante es el que proviene del Estado, tanto provincial como nacional, a través de empleos en los municipios y planes sociales, tanto que en algunos casos es el ingreso más importante de la familia, pasando a segundo plano el de la producción agropecuaria.

Hay que señalar además que la industria del turismo es incipiente en la zona estudiada. Si bien hay numerosas plazas hoteleras en la ciudad de Belén, el turismo que llega es de paso hacia zonas

\footnotetext{
${ }^{4}$ Por ejemplo, en cuanto a la oferta de trabajo, durante la etapa de construcción de la infraestructura se incorporaron 4500 operarios, pero esa cifra se redujo a 700 durante la primera etapa de producción. Actualmente, de las 1383 personas empleadas son catamarqueños el $40 \%$ (de toda la provincia, algunos de Belén). Álvarez e Ibañez: (2013:172)
} 
promocionadas por sus paisajes de altura en Antofagasta de la Sierra. En Villavil funciona una hostería dependiente del estado provincial desde hace 4 años, pero con poca demanda y en Laguna Blanca se inauguró en 2013 otra hostería provincial, también con pocos visitantes.

Por esta historia de aislamiento tanto geográfico como de políticas económicas excluyentes, en el departamento Belén todavía estaríamos en presencia de resabios de los que Claude Fischler llama "viejos ecosistemas domésticos diversificados", refiriéndose al tipo de producción agrícola que se desarrollaba antes de la modernización de la agricultura y la industrialización agro-alimentaria. Estos ecosistemas de producción para auto subsistencia y para un comercio regional, se caracterizan por la diversidad de sus productos, en contraposición a la especialización de la producción a gran escala.

Finalmente, es necesario destacar que existen diferencias notables entre los pueblos de los valles y de la puna, aún cuando la distancia en kilómetros que separa a Barranca Larga (el valle más cercano a la puna) y Laguna Blanca se de apenas 70 kilómetros. En la Puna, la altura, la gran amplitud térmica, la escasez de lluvia, hace que la actividad productiva humana sea restringida, principalmente ganadera con cría de cabras, ovejas, llamas y vicuñas, y comercialización de algunos derivados. En Laguna Blanca los habitantes del pueblo están organizados en una cooperativa que aprovecha la valiosa lana de estos animales, a través de un sistema de captura y esquila que retoma técnicas precolombinas, el encierro o Chaku, De ese modo se ha evitado la caza de las vicuñas que las ponía en peligro de extinción. El chaku se lleva a cabo cada año en noviembre, con el apoyo de la Dirección de ganadería de la provincia y el Instituto Nacional de Tecnología Agropecuaria. En la zona de los valles las condiciones climáticas mejoran pero se mantiene la escasez de lluvias lo que hace que la agricultura dependa fuertemente de la disponibilidad de agua. La actividad productiva es más variada, el cultivo de la vid y de la nuez, junto con el olivo y las aromáticas son las más importantes tanto en volúmenes de producción como en los beneficios directos e indirectos generados (Alvero e
Ibáñez, 2013). También se producen forraje, granos, frutales y hortalizas para autoconsumo.

Los puneños han permanecido todavía más aislados que los vallistas: hasta mediados de la década del 80 del S XX el comercio entre Villavil y Laguna Blanca se realizaba a través de caravanas de burros o mulas, no había camino para automóviles. Uno de nuestros entrevistados recuerda vívidamente las dificultosas travesías realizadas con su padre llevando granos, harina, frutas, panes y trayendo de Laguna carne y lana. En Laguna Blanca el ritual de agradecimiento a la Pachamama se realiza en cada celebración, cosecha o esquila, lo cual no sucede entre los vallistas en los que el culto a la Pachamama no está presente. En nuestra etnografía constatamos que los vallistas y los puneños se asumen diferentes, los vallistas con costumbres más similares a las de la ciudad de Belén o Catamarca. Hay por parte de los vallistas cierta mirada despreciativa a los puneños. Mientras que los puneños exhiben un orgullo distante y marcan a su vez su diferencia.

\section{Modos de resignificación y vigencia de la cocina tradicional}

Apenas iniciado el trabajo de campo, vimos la dificultad que implicaba calificar a una comida como tradicional. ¿Cuándo un plato se considera como parte de la cocina tradicional? ¿Cómo llega a entrar en ese repertorio? ¿Por qué algunos alimentos forman parte de este repertorio y otros no? A partir de los datos obtenidos en la etnografía, trataremos de responder a estas preguntas.

Identificamos un primer rasgo diferencial de lo que se considera comida tradicional que pasa por la comensalidad, entendida como la ocasión y el modo en que estas comidas se consumen y se comparten (Aguirre, 2004). Vamos a tomar este concepto y lo vincularemos con una sugerencia de Arjun Appadurai. Este autor señala para el caso de la comida de la India que "la emergencia del enfoque gustativo de la alimentación" sucede cuando el plato se independiza de sus significados morales y médicos; es entonces cuando pasa a ser valorado desde el punto de vista del gusto, 
del sabor, de sus características en función de otros sistemas de valor (1988:5). Appadurai hace este señalamiento en el marco de su reflexión sobre cómo se construyen los libros de cocina y de qué manera una preparación alimenticia entra a formar parte de un libro. Advierte que los procesos son complejos, dependiendo entre otras cosas del lugar de la palabra escrita en las diferentes sociedades, además de las particularidades de su régimen alimenticio. Sin embargo en los diferentes casos la comida ha pasado por un proceso de distanciamiento tal que logra ser cargada con significaciones que la hacen propicia para ser representativa de un sistema o modo culinario. Retomando esta idea podemos decir que gran parte de los alimentos que nos fueron señalados como tradicionales han sufrido un proceso de re-significación y re-valoración, en más de un sentido. El análisis de estos procesos de resignificación nos permitió reconocer tanto el carácter "tradicional" de las preparaciones alimenticias relevadas como sus modos de vigencia, que son diversos. A continuación trataremos de describir esos modos de resignificación y vigencia, ejemplificándolos con algunas de las preparaciones relevadas:

a. Una primera distinción se refiere a alimentos que se resignifican como tradicionales cuando se independizan de su lugar originario dentro de la dieta.

La mayoría de los alimentos que se relevaron han sido en algún momento parte de la dieta cotidiana de la vida campesina, antes de que la misma sea provista con alimentos de origen mayormente industrial. Cuando estos alimentos pueden ser reemplazados fácilmente por productos industrializados adquieren un nuevo sentido. En la ciudad de Belén sucede con todas las variedades de panes "criollos" o caseros, que se consumen por gusto o disfrute, teniendo en cuenta que para el pan cotidiano están las panaderías ${ }^{5}$. Existe una amplia variedad de panes caseros salados y dulces que se hacen en horno de barro; algunos como el pan dulce y la torta de turrón incluyen el uso de arrope, principalmente de uva. Estos panes caseros son

\footnotetext{
${ }^{5}$ Eso no es así en pueblos más pequeños donde todavía se hace el pan en las casas porque no hay panadería industrial o no llega el pan de Belén
}

producidos por familias que hacen de esta actividad una fuente de ingresos importante, produciéndolos al menos dos veces por semana.

b. Encontramos un conjunto de comidas consideradas tradicionales que no forman parte de la dieta cotidiana sino que se preparan para ocasiones especiales, y que esto aparentemente ha sido así desde que hay memoria. Es decir, son platos que siempre se hicieron para celebraciones y fiestas, tales como fiestas de la comunidad (religiosas y cívicas) y fiestas familiares y que siguen preparándose solamente en estas ocasiones. En Villavil, Los Morteritos y Laguna Blanca, es característico hacer para las fiestas patronales un cordero o cabrito entero al horno de barro, cuya boca se tapa con barro y piedra y se deja cocer adentro. Los condimentos varían de pueblo o de familia, pero mayormente son sal, un poco de vinagre, comino, orégano y pimentón. En Laguna Blanca y Los Morteritos los rellenan además de papas, cebolla, pimientos y otras verduras disponibles en elmomento. El dispendio que supone consumir la carne así y no aprovechada en guisados, sopas o locros, hace que esta preparación sea excepcional y festiva. Las fiestas patronales son la ocasión preferida por los familiares que viven lejos para volver de visita al pueblo, y estas comidas se hacen en su honor. Si la fiesta incluye números musicales o feria, también se sirve a los visitantes no familiares estas comidas, en improvisados comedores en las galerías y patios de las casas. En Belén el Api zapallo, un plato a base de puré de zapallo con cebolla, morrón, tomate y queso, se consume sobre todo en Semana Santa, cuando se proscribe la ingesta de carnes; el resto del año difícilmente se prepara. Si la fiesta es en verano, otro de los platos preferidos es la humita.

La humita también aparece como plato fuera de la dieta cotidiana, motivo de reunión familiar o de amigos, claramente estacional, en el tiempo en que maduran los choclos.

c. Hay otros alimentos que incorporamos en el repertorio de la comida tradicional que si bien se siguen haciendo para las ocasiones vinculadas a la reproducción de la vida campesina o comunitaria, 
también hay ocasiones en que se vuelven excepcionales o festivos: son preparados y compartidos por su propio disfrute, tal es el caso del gigote, el mote y la cabeza guateada. El gigote ${ }^{6}$ es una comida que se hace poniendo en una olla, en capas, rebanadas de pan casero, de queso criollo, de papas, cebollas, huevos duros y carne previamente asada y picada. A medida que se arma la olla se moja con una salsa a base de agua y pimentón, comino y ají picante, luego se deja cocinar por una hora. El mote o mote amanecido es una especie de locro sin zapallo y de maíz blanco entero, poroto manteca y carne de vaca, que se cocina toda la noche en fuego de leña. La cabeza guateada ${ }^{7}$ consiste en una cabeza de vaca, sin cuero, que se sala, se envuelve en arpillera y se entierra en un pozo previamente calentado, se tapa y se deja cocinar por lo menos 8 horas. Luego se come sobre una mesa, cada comensal va sacando trozos de la carne directamente de la cabeza, acompañada con pan y vino. Los tres son platos económicos y "rendidores", además de nutritivos: de una cabeza pueden comer de 8 a 10 personas. Los tres se preparan cuando hay motivo para reunir a un grupo grande de comensales, por eso se hacen como culminación de un trabajo que exige gran esfuerzo físico y muchos participantes, como las segadas o la loza de una casa. También se consume cuando van a las corridas, a buscar animales, lo que antes se llamaban campeadas. Otra ocasión es en la segada de trigo o de cebada, en las fincas alrededor de la ciudad. Durante la siega se corta el trigo y se emparva, lo mismo la avena y la cebada. La siega dura todo el día y parte de la tradición es la comida que se servirá: gigote, mote o cabeza guateada.

Pero además de esas ocasiones, ahora también se ofrece gigote en alguno de los restaurantes de Belén, sobre todo los domingos, o lo preparan las familias que hacen comida para vender. El mote también es comida de domingo y últimamente se ha vuelto costumbre entre los jóvenes los sábados a la madrugada, después del baile o la salida habitual, concurrir a casa de familias que preparan mote; lo consumen allí mismo, en la

\footnotetext{
${ }^{6}$ El origen de esta comida parece ser colonial, como vimos más arriba.

${ }_{7}$ Cocinar en un pozo caliente o con piedras calientes es una técnica que posee registros prehispánicos en varios sitios de Sudamérica (Coe,S, 2004)
}

cocina, el patio o el comedor de la casa. En cuanto a la cabeza guateada, es tradición en Belén comerla 1 de mayo, celebrando el día del trabajo, o entre amigos, sobre todo en invierno, como motivo principal de la reunión (reunirse a comer cabeza guateada).

Es decir, estos alimentos comparten los sentidos tanto de practicidad y nutrición como de disfrute y motivo de sociabilidad. Creemos que en la medida en que los ingredientes estén disponibles y accesibles, y en la medida en que haya motivo de reunir a numerosos comensales (ya sea por trabajo o por disfrute de compartir la comida y la compañía), ambos usos o sentidos van a seguir vigentes.

d. Nos encontramos también con comidas que ya no se preparan y que sólo quedan en la memoria de los mayores. Es el caso del tulpo y el sanco en Laguna Blanca y la poliada en Belén y Villavil. En todos estos casos la base de la preparación es harina, grasa y especias, con variaciones entre los diferentes pueblos o familias. El tulpo se preparaba calentando grasa pella en una olla de barro y agregándole harina para cocerla y finalmente agua, condimentando luego con comino y pimentón. Es decir, responde a la exigencia de poder ser preparados rápidamente, en la intemperie y que no haya significado dificultades para cargar los ingredientes. La poliada es una versión del tulpo pero preparada con afrecho.

Estas preparaciones han sido resignificadas cargándolas de valores negativos: comida de pobre, poco sofisticada y "de otro tiempo" (no moderna). Cuando formaban parte de la dieta cotidiana, ya traían alguna marca socialmente negativa, pero se seguían consumiendo, por ejemplo en la ciudad de Belén una de las personas entrevistadas, señora de 90 años perteneciente a la pequeña burguesía rural, recordaba que cuando era niña tenía prohibido comer tulpo, porque era la comida que comían los peones, entonces ella y su hermana lo hacían a escondidas de sus padres. Actualmente aparentemente ha dejado de ser también comida de peones.

Otro caso son golosinas hechas con harina de algarroba, maíz capia, arropes, que los niños llevaban junto con pochoclo o florcitas de maíz, para comer 
durante el pastoreo. Estas golosinas perdieron la batalla frente a las golosinas tradicionales, que se compran hechas y están sancionadas positivamente desde la televisión y con atractivos envoltorios y promociones.

El sanco o sunco es otro alimento que se recuerda pero que casi no se hace o consume en los pueblos visitados. Se hacía con maíz molido (a veces con polenta) tostado y cocido con grasa pella y especias. Como vimos más arriba, una de nuestras entrevistadas en Laguna Blanca narró un recuerdo de infancia en el cual el sunco era utilizado por su madre para dar de comer al viento y aplacarlo, cuando necesitaba montar su tejido en el telar del patio. ${ }^{8}$

Las comidas a base de maíz parecen haber perdiendo vigencia, con excepción del mote y del locro, pero estos, como vimos, como parte de la alimentación festiva, no cotidiana. En guisos y sopas, el maíz, incluso el frangollo (maíz molido en trozos pequeños) fue reemplazado por los fideos y el arroz. En varias ocasiones nuestros entrevistados manifestaron que antes comían más maíz y que ahora se lo usa para los animales. Doña Elodia, de 89 años, quien ha vivido toda su vida en Villavil y prepara su mazamorra del modo más tradicional, da cuenta de que el maíz como base de la alimentación compite hoy con productos industrializados como fideos y arroz, con los que se preparan guisos y sopas: "El locro es más alimento dice doña Elodia-, con tripa gorda, yo con eso me he criado. Yo he trabajado mucho semillando el maíz, eran cuatro o cinco yuntas de bueyes. Antes no había otra cosa, por ahí pimiento, papa, nada más. Antes el maíz lo apreciaban muchísimo, lo compraban mucho esa gente del norte de la Laguna, lo cambiaban por carne de majada, de chivo, de cordero, de llama, traían para cambiar por maíz. Lo apreciaban mucho y ahora no. Ya ve que aquí estaban por cosechar el maíz y no había quién lo saque, han contestado que no son gallinas para comer maíz. Dichosos de ustedes que tienen. Yo no, yo no voy a decir que no voy a comer maíz, nosotros

\footnotetext{
8 "Mi mamá sabía hacer el tulpo y sacar un pocazo así en el cucharón y ponerlo ahí afuera, y con tierra sabía sulfatarlo, que se vaya vaporeciendo para que coma el viento, y llamaba -- sabía llamarse Anselmo el viento: "Vení Anselmo, comé!! ¡Dejanos trabajar!", sabía gritarle, yo me acuerdo todo: j"Quiero poner mis telas, dejame, dejame, comé!" Sabía ir a verlo ella al tulpo y ... había poquito. Yo sabía creer que se lo había comido el viento."(Julia Guerra, 70 años, Laguna Blanca)
}

estamos acostumbrados, le digo, porque el maíz en todo caso yo lo hago locro, lo hago mazamorra y a veces también así para... No, que tienen con qué comprar fideos, yo a veces no tengo con qué comprar así que a veces tengo que hacer lo que alcanza. Así que lo he tenido que echar a los animales. Nadie quería conchabarse".

e. Entre los alimentos que socialmente están resignificados de manera negativa, hay algunos se siguen consumiendo, pero no nos fueron ofrecidos de inicio como parte del repertorio de cocina típica o tradicional, no por estar "normalizados" y por lo tanto invisibles dentro de su dieta cotidiana, sino por una actitud de cierto pudor: sólo aparecieron a partir de nuestra pregunta puntual por su consumo, y después de haber compartido con nosotros no sólo una comida sino la actividad de prepararla en su cocina, es decir, el alimento apareció cuando se había establecido una mutua confianza y nuestros entrevistados habían valorado el tipo de interés que teníamos por el tema. Estaríamos entonces frente a una clase de consumo más íntimo, al interior de algunas familias. Estos alimentos son el ancacho, el chilcán, la cochada y la ulpada en Laguna Blanca. El ancacho es una especie de pan que se prepara cuando se carnea un animal, mezclando sangre con el harina y especias, y poniéndola a cocer sobre una superficie caliente. Si se hace en el cerro o "en los puestos"9, se lo prepara sobre una piedra caliente, en las casas sobre una plancha o sartén. Es de rápida preparación y puede ser llevado cuando se está pastoreando los animales. El chilcán, la cochada y la ulpada son preparaciones a base de harina cocida y agua, se diferencian por la cantidad y temperatura del agua. El harina cocida es un tipo de harina que se hace tostando los granos (de maíz o de trigo) antes de molerlos.

Su sabor se lo da, además del tostado, el hecho de que se trata de la harina criolla, resultado de moler el grano entero, con su cáscara.

En Villavil y Laguna Blanca el chilcán y la cochada parecen haberse resignificado negativamente

\footnotetext{
${ }^{9}$ Los puestos son pequeños ranchos o refugios donde los pastores pasan una temporada cuidando a sus animales. Están alejados del pueblo, generalmente en los cerros. Hay algunas familias que tienen parientes que viven en los puestos de manera permanente, en general con familia y niños pequeños.
} 
como comida de "coya", categoría que está cargada de connotaciones de "atrasado", "ignorante" y también "pobre". La harina cocida no es fácil de conseguir en el pueblo, ni siquiera en Villavil, a $80 \mathrm{~km}$. Antes se producía localmente, tostando el maíz en ollas de barro y moliéndolo en las casas o en el molino del pueblo o pueblo vecino. Esto se hacía cuando se producía sistemáticamente trigo y maíz. Ahora encargan el harina cocida al camión, que la trae de Santa María, donde hay molinos más industriales. Es decir, esta familia vence las dificultades de su disponibilidad, se toma el trabajo de conseguir harina cocida, para seguir consumiéndola. Ellos son padres jóvenes de niños en edad escolar y recuerdan que sus propios padres les daban chilcán o cochada de desayuno, y se lo dan a sus hijos, porque consideran ese desayuno, tanto con harina de trigo como con harina de maíz, es mucho más nutritivo que el mate o el mate cocido $^{10}$. La ulpada es una bebida refrescante hecha con un poco de harina cocida diluida en mucha agua fresca y endulzada con azúcar. Se recuerda su consumo como bebida refrescante y reparadora (la tomaban cuando volvían de cuidar los animales), pero ahora se la reconoce solamente como parte importante de la ofrenda a la Pachamama durante la fiesta en su honor cada 1 de agosto en Laguna Blanca. Aparentemente, se está volviendo alimento exclusivamente ritual.

Asimismo en Belén mientras esperábamos que se haga el api zapallo, nos ofrecieron harina cocida con azúcar que tenían en una bolsa de plástico, también ante nuestra pregunta por su consumo. En la ciudad de Belén no se conoce el chilcán, la cochada o la ulpada, el harina cocida se consume mezclada con azúcar, como golosina. El harina cocida se ha dejado de producir en esta ciudad y la que se consigue proviene de los molinos de Santa María, 100 km al norte de Belén y es difícil conseguirla en los comercios la región estudiada,

\footnotetext{
${ }^{10}$ Nuestro entrevistado narró que consumía harina cocida como desayuno antes de ir a la escuela o como merienda al regresar, en vez de tomar mate. Así la preparaban sus padres: "primero hervían el agua, después nos ponían un poquito de harina cocida en el jarro, un poquito de azúcar y encima el agua bien hervida, suficiente cantidad como para que salga ni tan seco ni tan blando. Se llamaba cochada, y era dulce y sabrosa, nos gustaba".
}

o circula en redes alternativas de comercialización que no hemos estudiado todavía. ${ }^{11}$

avisada de su llegada. Esta vez llegamos sin aviso a preguntar si tenía servicio, y nos respondió disculpándose que sólo tenía carbonada, que había quedado de su almuerzo familiar.

g. También pudimos observar nuevas comidas que utilizan quínoa, que se están haciendo a partir de la gestión de instituciones públicas como el INTA (Instituto Nacional de Tecnología Agropecuaria) y de programas de gobierno que fomentan la recuperación de la producción y consumo de este cereal de alto valor proteínico y que se adapta a las características geográficas de la zona. Si bien no registramos memoria de comidas con quínoa ni siquiera entre los ancianos, se sabe por estudios arqueológicos e históricos que era un cereal que se producía en las aldeas precolombinas de la región y que se mantenía en algunos pueblos incluso hasta fines del siglo XIX. Dos de los entrevistados optaron por preparar platillos con quínoa al solicitarles una comida tradicional de su pueblo, pero motivados por estas capacitaciones institucionales.

f. Hay también preparaciones que claramente se resignifican a partir de la mirada de los otros, esto sucede cuando el plato se comparte con personas que no forman parte del pueblo o región de origen. A la hora de definir a un plato como tradicional o propio o típico de la región quienes tenían más certeza eran los entrevistados que habían vivido fuera de su lugar de nacimiento. Un grupo numeroso de las mujeres y hombres entrevistados vivieron parte de su vida fuera de su pueblo, en Buenos Aires o en el sur del país (Patagonia) a donde partieron en busca de trabajo. Las personas que migraron, viviendo lejos de sus pueblos son los que, en la hostilidad de las grandes ciudades, encontraron a veces un motivo de orgullo o una fuente de trabajo en la preparación de sus comidas. Una de nuestras entrevistadas marcó como un momento destacable de su vida en los suburbios de Buenos Aires

11 En la ciudad de Belén había al menos dos molinos que trabajaron hasta la década de 1960, ya no trabaja ninguno; de allí los nombres de dos de los barrios de la ciudad: El Molino y Molino de Santa Rosa. El viejo molino de Santa Rosa sigue en pie; ha sido restaurado y puede visitarse. Está pegado a la falda del cerro, en medio de una hermosa arboleda. Los días de riego, el agua de la acequia sigue pasando debajo de la vieja construcción, golpeando las pesadas aspas de madera de algarrobo. 
el día que preparó unas empanadas tal como se las hacía en su pueblo, que fueron celebradas por sus vecinos, a partir de lo cual se estableció no sólo la posibilidad de vender habitualmente esta comida sino también el sentirse halagada por su saber y orgullosa de su procedencia.

En este grupo incluimos además algunos alimentos a los que nuestra mirada de investigadoras marcó como típico o tradicional, en el sentido de diferentes a las preparaciones más comunes a estilo de vida urbano del resto del país. Es el caso, por ejemplo, de la carbonada en Laguna Blanca, similar a una sopa con zapallo, carne o charki, arroz, cebolla de verdeo. A esta comida la probamos en la casa de una de nuestras entrevistadas, con quien ya habíamos tenido varios encuentros. Ella a veces prepara comida para los ocasionales turistas, previamente haber sido avisada de su llegada. Esta vez llegamos sin aviso a preguntar si tenía servicio, y nos respondió disculpándose que sólo tenía carbonada, que había quedado de su almuerzo familiar.

g. También pudimos observar nuevas comidas que utilizan quínoa, que se están haciendo a partir de la gestión de instituciones públicas como el INTA (Instituto Nacional de Tecnología Agropecuaria) y de programas de gobierno que fomentan la recuperación de la producción y consumo de este cereal de alto valor proteínico y que se adapta a las características geográficas de la zona. Si bien no registramos memoria de comidas con quínoa ni siquiera entre los ancianos, se sabe por estudios arqueológicos e históricos que era un cereal que se producía en las aldeas precolombinas de la región y que se mantenía en algunos pueblos incluso hasta fines del siglo XIX. Dos de los entrevistados optaron por preparar platillos con quínoa al solicitarles una comida tradicional de su pueblo, pero motivados por estas capacitaciones institucionales.

\section{Vigencia de la cocina tradicional, comensalidad y memoria.}

Después de la diferenciación de los tipos de alimentos que incorporamos dentro de nuestro relevamiento de comidas locales tradicionales, intentaremos sistematizar sus rasgos pertinentes y el sentido de su recuperación y estudio.

En esta cocina estudiada, encontramos que el rasgo fundamental para definir si un plato ha entrado dentro del repertorio de lo que se considera como comida "propia" es su comensalidad: no son alimentos que se consumen a solas, individualmente, sino de manera colectiva. Es una cocina fuertemente ligada a la celebración de festividades (cívicas o religiosas) de la comunidad o de las familias dentro de la comunidad, pero también se prepara especialmente para otras ocasiones en las que se reúne un grupo numeroso, como el trabajo colectivo, en las cosechas, en finales de obras de construcción, etc. Los trabajos colectivos incluyen el cierre con una comida en particular, y ese también es un atractivo. La cocina tradicional parece nutrir los vínculos sociales al mismo tiempo que los genera.

Es notable la importancia de la alimentación marcada como propia, para los habitantes de la región visitada. Se trata de recetas que se transmiten como valioso legado de una generación a otra y alrededor de la cual se generan opiniones ya que es objeto reflexión y de control, a través de su aprobación o desaprobación según si el plato realizado es fiel a la memoria común de su sabor, aspecto y modo de consumo. Retomamos aquí la sugerencia de Marcelo Álvarez: "Una cocina no puede existir a menos que se cuente con una comunidad que prepare sus platillos, los coma, opine sobre ellos y sostenga diálogos en torno a esas opiniones" (Álvarez, 2005:19). Creemos que efectivamente se trata de una cocina viva, creativa y objeto de interés por los que la preparan y la consumen. Por eso mismo, estos alimentos parecen ofrecer un fuerte sentido de pertenencia, una idea de comunidad que va más allá de los gustos individuales y familiares, y que es objeto de apreciación y a la que hay deseo de reconocer y honrar periódicamente, a través de la preparación de alimentos sentidos como propios.

En esta cocina las recetas se transmiten de manera oral, de una generación a otra: no encontramos libros de recetas locales en el momento de nuestra investigación. Se trata de una cocina de pocos 
ingredientes de los que se aprovecha al máximo y que usa un repertorio restringido y característico de condimentación (comino, orégano, pimentón y ají). Pero, al mismo tiempo, presenta variaciones no sólo entre pueblos vecinos sino también entre cocineras o cocineros, y esta variación es motivo de discusión porque cada quien supone que la suya es la correcta forma de preparar un determinado plato. En ese sentido es frecuente que se señalen a algunas personas como depositarias de ese saber, quienes son reconocidos por "saber hacer" esas preparaciones de la manera más lograda, por lo cual existe un régimen de prestigio asociado a este tipo de comidas. Ese lugar del que sabe está en permanente disputa.

Otro rasgo es que la mayoría de los ingredientes que las investigaciones señalan como propios del mundo prehispánico siguen vigentes: papa, camélidos, maíz, poroto, quínoa, amaranto, ají, algarroba. Según Marcelo Álvarez, las crónicas y memorias mencionan cuatro comidas que al parecer constituían los principales platos de la cocina prehispánica del noroeste: mote, locro, tulpo y picante (Álvarez, 2005). Las dos primeras continúan haciéndose en diferentes formas; el "picante" no aparece con ese nombre, aunque el ají es condimento central en muchas preparaciones. El tulpo aparentemente ya no se hace, aunque todavía hay memoria de su preparación y su sabor, y también discusiones acerca de la manera correcta de hacerse. También existen formas de preparación que aparecen en las crónicas de las cocinas precolombinas como el de la cabeza guateada, y el ancacho (Coe, 2004). E nuevo uso de la quínoa como rasgo local es producto de políticas de estado orientadas al mejoramiento de la oferta alimenticia para las poblaciones locales, pero apenas se está implementando y se ofrece mayormente como atractivo turístico para los ocasionales visitantes, resaltando su carácter de "alimento prehispánico" como valor.

En la cocina relevada, al menos una parte de los ingredientes y especias necesarios para producir el alimento son de producción familiar, local o regional. (Ver Anexo 2). ${ }^{12} \mathrm{~A}$ medida que nos alejamos del área

\footnotetext{
${ }^{12}$ En Belén los platos marcados mayoritariamente como propios (e mote y el gigote) son realizados con ingredientes que se compran en los supermercados o comercios provistos desde otros
}

urbana de la ciudad, lo producción local de los ingredientes es un dato más importante porque supone su disponibilidad. Por lo tanto sigue siendo en gran medida fuertemente estacional: depende de la temporada de producción de los ingredientes. Pero esta disponibilidad no es determinante ya que hemos visto cómo algunos ingredientes no son de fácil acceso y sin embargo se encuentra la manera de disponer de ellos En esta cocina también conviven sentimientos ambiguos de orgullo por los platos típicos al mismo tiempo que vergüenza o desprecio por lo que consideran comida de indio o de pobre, o poco moderna. Aquí es posible advertir algunas diferencias generacionales, que habría que corroborar con un estudio etnográfico más profundo. En nuestro caso, la mayoría de los ancianos entrevistados marcaron su incomodidad o francamente su desprecio por la comida industrial y los alimentos "que trae el camión", como el fideo o el arroz; al tiempo que se lamentaban todo lo que se ha dejado de hacer en relación a la producción de alimentos para consumo propio, desde la siembra de maíz hasta la preparación de quesos caseros. La devaluación del maíz como alimento está aquí apenas apuntada pero merece un estudio más detallado, porque no se trataría del maíz por sí mismo: creemos que lo que aparentemente está siendo devaluado es la idea de la producción para consumo propio. Esto lo notamos en varios testimonios de adultos entrevistados. En esos testimonios, aparece la idea de que los jóvenes no quieren hacer la tarea agrícola, que ahora "todos quieren trabajar", refiriéndose al trabajo asalariado fuera de la casa. No se nombra como "trabajo" a la tarea labrar la propia tierra.

La comida tradicional así considerada puede ser entendida como un ejercicio de la memoria, porque preparándola y consumiéndola, en esas prácticas, en ese mismo momento, se la recuerda. Se recuerda cocinando y comiendo en compañía, se evoca con los sabores y los aromas. Maurice Halbwach, en sus estudios seminales sobre memoria, al distinguir la Historia de la memoria colectiva, enfatiza que, a diferencia de aquella, que destaca los acontecimientos, lo que se sale de lo común en la vida de un grupo, "en la

provincias, pero las dos especias fundamentales para su elaboración (sin las cuales no sería posible realizarlos, el comino y el pimentón, son de producción local). 
memoria colectiva las semejanzas pasan (...) al primer plano" (2004: 8). En la memoria colectiva es central el tema de la duración como experiencia específica del tiempo en los seres humanos, diferente a la medida del tiempo, a la acción de medirlo. Existen platos, preparaciones culinarias que revelan no sólo años sino siglos de existencia, como vimos con comidas de origen prehispánico o colonial. Se reeditan una y otra vez, y aunque en cada ocasión sufren modificaciones, al mismo tiempo se actualizan, se mantienen, se busca deliberadamente la reproducción del sabor, del aspecto que se conocía, que fue aprendido. La acción de repetir, rehacer el plato, el postre, la bebida, creemos que es una práctica de memoria, memoria materializada, que es de naturaleza diferente a la memoria discursiva, la que se hace con los relatos, a través de las palabras.

Pero Halbwach también ha demostrado que una tradición no sobrevive sino encuentra un sentido dentro de los marcos sociales del presente: "los marcos sociales son los instrumentos que la memoria colectiva utiliza para reconstruir una imagen del pasado acorde con cada época y en sintonía con los pensamientos dominantes de la sociedad" (2004: 10). Es por eso que se vuelve muy inquietante preguntarse por qué y cómo es que una forma de preparación de un alimento que tiene un linaje de siglos sigue teniendo sentido para un grupo: existirían, por lo tanto, marcos sociales que habilitan la vigencia de una forma de alimentación, o al menos de una forma de preparación de algunos alimentos. Esos marcos, creemos, son dados por la vigencia, todavía, de la práctica de la producción propia de los alimentos. Creemos que lo que esta cocina evoca es un modo de vida que ahora está en crisis, y del que la comida es testimonio palpable: el modo de vida campesino, entendiendo a este término como el que señala a pequeños productores rurales que producen para su propio sustento y para mercado local, cuyos ritmos de vida están regidos principalmente por las estaciones y el clima y cuyas estrategias y prácticas de reproducción social son fuertemente colectivas. A partir de nuestra etnografía, encontramos que esto que llamamos modo de vida campesino genera sentimientos y opiniones ambiguas: al mismo tiempo que es practicado y añorado, también es despreciado y desvalorado: entre los jóvenes, es mejor visto cobrar un sueldo en un empleo público que ser labrador, pero se manifiesta orgullo por las comidas hechas a la vieja usanza y con ingredientes locales. Nuestro interés por relevar las comidas tradicionales locales y desentrañar sus mecanismos de vigencia, es para nosotros un modo de entender las maneras en que la cocina local resiste a la uniformización de los mandatos de la industria y del mercado de la alimentación, con la consecuente enajenación de las personas frente a lo que se come. Y de ese modo indagar también cómo los pequeños productores rurales se ven a sí mismos y cómo sostienen su cada vez más difícil práctica de producir los propios alimentos. La memoria colectiva aparece así como el resguardo de un modo de vida otro que aunque devaluado sigue siendo parte del bagaje de saberes populares que pueden actualizarse cuando sea necesario. Los alimentos tradicionales condensan esa sabiduría, en forma de memoria que se come.

\section{Referências}

AGUIRRE, Patricia. Ricos flacos y gordos pobres. La alimentación en crisis. Buenos Aires: Capital Intelectual, 2004.

ALFARO, Alfonso. Los espacios de la sazón. La sombrita, el antojo y el altar. En: Cuadernos de Patrimonio Cultural y turismo. Tomo 1. México: CONACULTA, 2002

ALVAREZ, Marcelo. Las recetas de cocina, arte y parte de la tradición. En: Patrimonio Cultural y Turismo, Cuadernos 7, México: CONACULTA, 2004

ALVERO, Luis Alejandro; IBÁÑEZ y Carlos Humberto. Historia económica de Catamarca 1800-2010. Catamarca: Editorial Científica Universitaria de la Universidad Nacional de Catamarca, 2013

APPADURAI, Arjun. How to make a national cuisine: coockboocks in contemporary India. En Comparative Studies in Society and History. Vol 30, No 1 (pp 3-24). Cambridge: Cambridge Univesity Press, 1988

BAZAN, Armando Raúl. Historia de Catamarca. Buenos Aires: Plus Ultra, 1996.

COE, Sophie D. Las primeras cocinas de América. 1ra ed. 1994. México: FCE, 2004

DOUGLAS, Mary. Las estructuras de lo culinario. En Contreras, Jesús (comp). Alimentación y cultura. Necesidades, gustos y costumbres. México: Alfaomega editores, 2002. 
FISCHLER, Claude. Gastronomía y gastro-anomía: sabiduría del cuerpo y crisis biocultural de la alimentación contemporánea. En Contreras, Jesús (comp). Alimentación y cultura. Necesidades, gustos y costumbres. México: Alfaomega editores, 2002.

DE SAN PELAYO, Gerónimo de San Pelayo. Libro de cocina del hermano fray Gerónimo de San Pelayo. México, siglo XVIII. México: CONACULTA- Dirección general de culturas populares. Colección recetarios antiguos, 2003

GOODY, Jack: Alimentación industrial: hacia una cocina mundial. En Contreras, Jesús (comp). Alimentación y cultura. Necesidades, gustos y costumbres. México: Alfaomega editores, 2002.

HALBWACHS, Maurice. Los marcos sociales de la memoria. Barcelona: Anthropos, 2004

LLADONOSA I Giro, Josep. El libro de la cocina catalana. Barcelona: Alianza, 1990

Documentos:

MINISTERIO DE PRODUCCIÓN Y DESARROLLO DE CATAMARCA. Estrategia provincial del sector agroalimentario de Catamarca. Catamarca: Gobierno de la provincia, 2009.

ANEXO I: Listado de alimentos relevados

Platos salados: Ancacho, Cordero o cabrito enteros al horno de barro, Api Zapallo, Cabeza Guateada, Cazuela de gallina, Chanfaina, Charqui, Charqui molido, Empanadas, Gigote, Guiso de charqui de llama, Humita en chala, Morcilla de carne de Ilama, Mote amanecido, Mote de haba, Pastel de papa con charqui, Pastel de choclo, Paté de hígado con arrope de uva, Poliada, Queso de pata, Sanco o sunco, Sopa, Sopa con charqui, Tortilla de romasa al rescoldo, Tulpo

Panes: Levadura casera, Pan criollo, Pan de zapallo, Pan shema, Pan de la puerta I'horno

Tortilla

Postres y dulces: Cochada, Chilcán, Dulce de durazno, Espesao, Mazamorra, Melcocha de uva, Quemadillo, Tostado, Turrón de capia

Arropes: Arrope de uva, Arrope de tuna, Arrope de chañar

Bebidas: Agüita de picaflor, Aloja, Añapa, Chicha, Jacarandá, Licor de muña muña, Ulpada

Vino patero

Quesos: Queso criollo, Quesillo 
ANEXO 2

CUADRO: Origen de ingredientes por alimento según localidade

\begin{tabular}{|c|c|c|c|c|c|}
\hline $\begin{array}{l}\text { Localid } \\
\text { ad }\end{array}$ & Alimento & $\begin{array}{l}\text { Producción } \\
\text { propia }\end{array}$ & $\begin{array}{c}\text { Producción del } \\
\text { pueblo }\end{array}$ & $\begin{array}{l}\text { Producción } \\
\text { Regional } \\
\text { (NO Catam.) }\end{array}$ & $\begin{array}{l}\text { Producción fuera } \\
\text { de la región }\end{array}$ \\
\hline \multirow{9}{*}{$\begin{array}{l}\text { Laguna } \\
\text { Blanca }\end{array}$} & Ancacho & $\begin{array}{l}\text { Llama, } \\
\text { cordero } \\
\text { cabrito }\end{array}$ & Cebolla & $\begin{array}{l}\text { Pimentón } \\
\text { Comino } \\
\text { Ají } \\
\text { Sal }\end{array}$ & \\
\hline & $\begin{array}{l}\text { Cordero o } \\
\text { cabrito al } \\
\text { horno } \\
\text { relleno }\end{array}$ & $\begin{array}{l}\text { Cordero } \\
\text { Papas }\end{array}$ & Cebolla & $\begin{array}{l}\text { Pimentón } \\
\text { Comino } \\
\text { Ají } \\
\text { Sal }\end{array}$ & \\
\hline & $\begin{array}{l}\text { Morcilla de } \\
\text { llama }\end{array}$ & Llama & Cebolla & $\begin{array}{l}\text { Pimentón } \\
\text { Comino } \\
\text { Ají } \\
\text { Sal }\end{array}$ & Ajo \\
\hline & $\begin{array}{l}\text { Guiso de } \\
\text { Charqui de } \\
\text { llama }\end{array}$ & Llama & Cebolla & $\begin{array}{l}\text { Pimentón } \\
\text { Comino } \\
\text { Ají } \\
\text { Sal }\end{array}$ & Fideos \\
\hline & $\begin{array}{l}\text { Ulpada, } \\
\text { Chilcan, } \\
\text { Cochada }\end{array}$ & & & $\begin{array}{l}\text { Harina cocida } \\
\text { de maíz } \\
\text { Harina cocida } \\
\text { de trigo }\end{array}$ & Azúcar \\
\hline & Espesao & & & & $\begin{array}{l}\text { Polenta } \\
\text { Azúcar }\end{array}$ \\
\hline & $\begin{array}{l}\text { Tortillas al } \\
\text { rescoldo }\end{array}$ & Grasa & & Sal & Harina de trigo \\
\hline & $\begin{array}{l}\text { Tostado y } \\
\text { Quemadillo }\end{array}$ & & $\begin{array}{l}\text { Hierbas } \\
\text { aromáticas }\end{array}$ & & \\
\hline & Jacarandá & & & Vino, naranja & Azúcar \\
\hline \multirow[t]{4}{*}{ Villavil } & $\begin{array}{l}\text { Locro de } \\
\text { trigo }\end{array}$ & $\begin{array}{l}\text { Zapallo } \\
\text { Acelga } \\
\text { Cebolla } \\
\text { blanca } \\
\text { Cebolla } \\
\text { verdeo } \\
\text { Maíz } \\
\text { Carne de vaca } \\
\text { Pimentón } \\
\text { Trigo }\end{array}$ & Comino & Sal & $\begin{array}{l}\text { Aceite } \\
\text { Queso cremoso }\end{array}$ \\
\hline & Mazamorra & Maíz & & Colpa & \\
\hline & $\begin{array}{l}\text { Panes } \\
\text { casero }\end{array}$ & Anís & $\begin{array}{l}\text { Grasa de vaca } \\
\text { Harina criolla }\end{array}$ & Arrope de uva & Harina de trigo \\
\hline & $\begin{array}{l}\text { Guiso de } \\
\text { quínoa }\end{array}$ & Quínoa & $\begin{array}{l}\text { Cebolla Blanca } \\
\text { Ajo } \\
\text { Tomate }\end{array}$ & Comino & Aceite \\
\hline
\end{tabular}




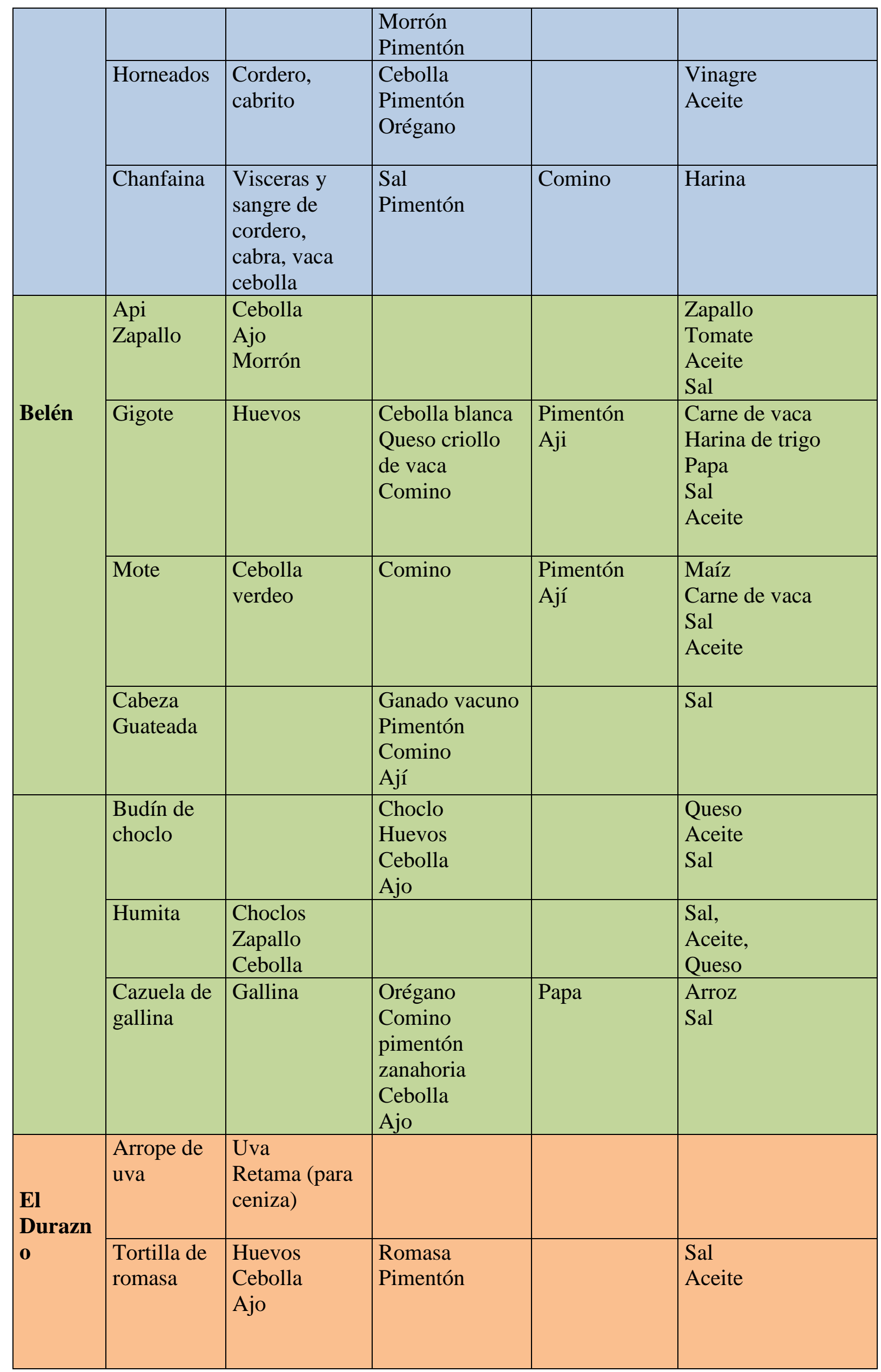


